\title{
PROPOSIÇÃO DE MODELO TEÓRICO PARA ESTUDO DE UNIVERSIDADES EMPREENDEDORAS
}

Sofia Maria De Araujo Ruiz ${ }^{1}$ Cristina Dai Pra Martens ${ }^{1}$

${ }^{1}$ Universidade Nove de Julho 


\section{PROPOSIÇÃO DE MODELO TEÓRICO PARA ESTUDO DE UNIVERSIDADES EMPREENDEDORAS}

Resumo: O objetivo deste artigo foi propor um conjunto de elementos que caracterizam as universidades empreendedoras. Foi revisitada a literatura, desde os artigos seminais até 2017, partindo de 289 estudos pesquisados, 13 artigos foram selecionados e analisados qualitativamente para a proposição do modelo teórico, os quais possibilitaram a compreensão das características das universidades empreendedoras. Os elementos teóricos foram agrupados e relacionados em dimensões que, após serem refinados, embasaram a proposição do modelo teórico para análise empírica das universidades empreendedoras. Esta análise possibilitou a compreensão das características das universidades empreendedoras que se transformam para atender às demandas da sociedade. Como sugestões de estudos futuros, destaca-se a necessidade de pesquisas empíricas para validar os elementos identificados e/ou agregar outros elementos que possam compor uma universidade empreendedora.

Palavras-chave: Universidade Empreendedora. Modelo teórico. Dimensões de Universidade Empreendedora. Empreendedorismo.

\section{Introdução}

Assim como as teorias sobre empreendedorismo expandiram e destacaram-se nas últimas décadas, as universidades também promovem um esforço para remodelar seus papeis e serem empreendedoras, a fim de servirem à sociedade na qual estão inseridas e serem acessíveis a todos.

O empreendedorismo e a educação são duas oportunidades que precisam ser alavancadas e interligadas para desenvolver o capital humano necessário para construir as sociedades do futuro (Volkmann et al., 2009), uma vez que o empreendedorismo é o motor que alimenta a inovação, a geração de emprego e o crescimento econômico e social.

A expressão 'universidade empreendedora' foi utilizada pela primeira vez por Clark (1998) em seu estudo 'Creating entrepreneurial universities: organisational path of transformation' que a define como aquela que realiza mudanças em sua estrutura e em sua cultura organizacional - reforçando seu núcleo de direção - que inova seus currículos, seus programas, suas fontes de financiamento - visando engajar-se em um sistema social com um futuro promissor. Para esse autor, a universidade empreendedora é mais social e busca ser inovadora e torna-se mais proativa, flexível e dinâmica na gestão de suas relações com a economia e com a sociedade, mesmo correndo riscos.

Gibb et al. (2013, p.25), citando Todorovic et al., 2005 e Wenger, 1998, afirmam que as universidades enfrentam um grande desafio e também novas oportunidades na criação de uma cultura empreendedora, uma vez que a massificação da educação, o financiamento público limitado (e decrescente), a competitividade global e as demandas em constante mudança da economia do conhecimento fazem com que as instituições de ensino superior sejam mais
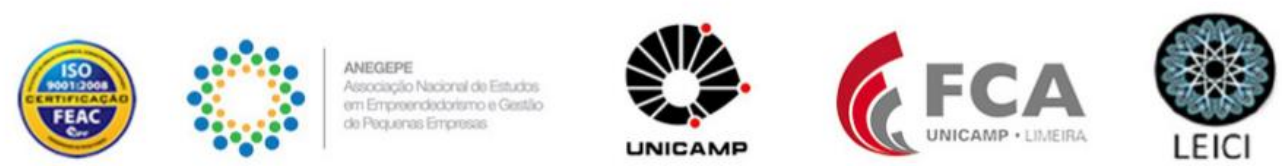
sensíveis ao desenvolvimento socioeconômico ambiental e, consequentemente, às atividades empreendedoras (Sam \& van der Sijde (2014).

Embora tenha sido concebida inicialmente como uma instituição transmissora do conhecimento, a universidade, mais tarde, adotou a função de geração de conhecimento (pesquisa); adquirindo uma 'segunda missão' (Etzkowitz, 2003). Nas últimas décadas, as universidades passam a adquirir a 'terceira missão', contribuindo para a sociedade e o desenvolvimento socioeconômico de maneira mais direta, transformando-se em uma universidade empreendedora (Etzkowitz, 2003; 2004).

Ampliar o foco das universidades tradicionais - baseados no ensino e pesquisa, "agregando à sua missão a atuação direta no processo de desenvolvimento econômico, cultural e social da sociedade" (Audy \& Ferreira, 2006, p.418), é o grande desafio de muitas universidades atualmente, uma vez que universidade empreendedora pode ser 'agente público global', ou seja, proporcionar o desenvolvimento das comunidades local, regional, nacional e internacional, por meio da criação de valor público (Weerts, 2007).

No Brasil, a educação superior tem o papel social de promover a formação cidadã (Brasil, 1996), principalmente no cenário atual - nominado de sociedade do conhecimento, mundo da informação e era da globalização - que apresenta desafios que impactam no modo de ser das universidades, na estrutura administrativa, nos currículos, na gestão financeira, na qualidade das pesquisas, rompendo fronteiras para a disseminação do conhecimento.

Identificar quais elementos são necessários para transformar uma universidade tradicional em uma universidade empreendedora é que se insere o objetivo deste artigo. Esta proposta de estudo contribuirá para responder como se configuram as universidades empreendedoras e apresentar um modelo teórico, a partir da literatura, sobre os elementos teóricos que compõem e caracterizam as universidades empreendedoras. Para tanto, optou-se pelo estudo de caráter teórico que contemplou a análise lexical e de conteúdo, a fim de avaliar a literatura mais abrangente sobre o tema, de modo a orientar futuras pesquisas sobre o modelo de universidade empreendedora.

Assim, o presente estudo está estruturado inicialmente com esta introdução, seguida da fundamentação teórica sobre universidade empreendedora. Após, é apresentada a metodologia empregada neste estudo e os resultados analisados empiricamente e discutidos ao final.

\section{Fundamentação Teórica}

Esta seção fornece uma visão geral da literatura existente e dos debates associados às conceituações contemporâneas sobre as universidades empreendedoras e o empreendedorismo universitário. Embora o campo da literatura seja extenso, esta visão geral revela uma lacuna crescente entre os debates sobre a expansão do termo empreendedorismo e a ampliação dos papéis exercidos pelas universidades.

$\mathrm{Na}$ literatura, é possível encontrar várias definições sobre universidade empreendedora e suas características. No entanto, encontrar uma definição única para universidade empreendedora é difícil e controversa, pois existe uma inestimável pluralidade de abordagens, que distinguem o estilo empreendedor em um processo multifacetado de melhoria contínua, portanto, é difícil definir diretrizes rígidas para a sua implementação (OCDE, 2012), dado que a diversidade das abordagens empreendedoras tomadas pelas universidades é uma das características mais importantes do conceito (Fayolle \& Redford, 2015).
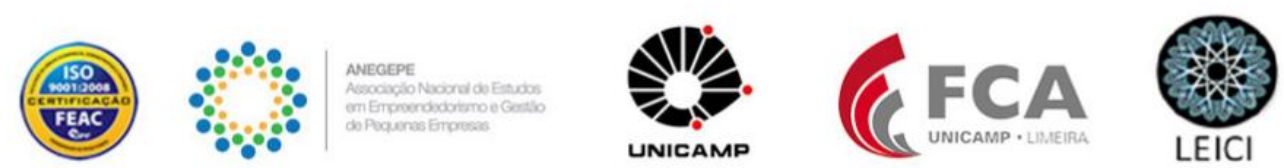
Na Figura 1, são apresentados alguns conceitos sobre universidade empreendedora identificados na revisão da literatura, desde os artigos seminais até 2017.

\begin{tabular}{|c|c|}
\hline Autor & Definição \\
\hline Etzkowitz (1983) & $\begin{array}{l}\text { Universidades que estão considerando novas fontes de fundos, como patentes, pesquisa } \\
\text { por contratos e entrada em uma parceria com uma empresa privada }\end{array}$ \\
\hline $\begin{array}{l}\text { Chrisman et al. } \\
\text { (1995) }\end{array}$ & $\begin{array}{l}\text { Universidade empreendedora envolve a criação de novos negócios por professores } \\
\text { universitários, técnicos ou estudantes. }\end{array}$ \\
\hline Etzkowitz (1998) & $\begin{array}{l}\text { Universidade empreendedora é uma instituição capaz de gerar uma direção estratégica a } \\
\text { seguir, formulando seus objetivos acadêmicos claros e transformando o conhecimento } \\
\text { gerado na universidade em valor econômico e social. São universidades que buscam novas } \\
\text { fontes de recursos, tais como a transferência de tecnologia }\end{array}$ \\
\hline Clark (1998) & $\begin{array}{l}\text { Universidade Empreendedora é uma instituição ativa e procura inovar na maneira como } \\
\text { conduz os seus negócios, visando a uma postura promissora de futuro. Elas tornam-se } \\
\text { universidades stand-up, ou seja, atores relevantes por si mesmos. }\end{array}$ \\
\hline Röpke (1998, p.2) & $\begin{array}{l}\text { Uma universidade empreendedora pode significar três coisas: a própria universidade, } \\
\text { como organização, torna-se empreendedora; os membros da universidade - professores, } \\
\text { estudantes, funcionários - tornam-se empreendedores; e a interação da universidade com } \\
\text { o meio ambiente (região), segue a abordagem empreendedora. }\end{array}$ \\
\hline Subotzky (1999) & $\begin{array}{l}\text { Universidade empreendedora caracteriza-se por mais parcerias mais próximas entre } \\
\text { universidades e empresas, por uma maior responsabilidade docente pelo acesso a fontes } \\
\text { externas de financiamento e por um ethos gerencial em governança institucional, liderança } \\
\text { e planejamento. }\end{array}$ \\
\hline Kirby (2002p. 2) & $\begin{array}{l}\text { "Universidades empreendedoras têm a capacidade de inovar, reconhecer e criar } \\
\text { oportunidades, trabalhar em equipe, assumir riscos e responder aos desafios". }\end{array}$ \\
\hline $\begin{array}{l}\text { Barnes et al. } \\
(2002)\end{array}$ & $\begin{array}{l}\text { A universidade empreendedora é uma entidade que oferece oportunidades, práticas, } \\
\text { culturas e ambientes favoráveis que incentivam e abraçam ativamente o } \\
\text { empreendedorismo, o qual faz parte da própria medula óssea dessas instituições. }\end{array}$ \\
\hline Etzkowitz (2003) & $\begin{array}{l}\text { A universidade empreendedora é uma incubadora natural, fornecendo estruturas de apoio } \\
\text { para professores e estudantes para iniciar novos empreendimentos. }\end{array}$ \\
\hline $\begin{array}{l}\text { Jacob et al. } \\
(2003)\end{array}$ & $\begin{array}{l}\text { Uma universidade empreendedora engloba tanto a comercialização (por exemplo, cursos } \\
\text { de educação complementar feitos sob medida, serviços de consultoria, atividades de } \\
\text { extensão) como a mercantilização (por exemplo, patentes, licenciamentos, faculdades ou } \\
\text { empreendimentos próprios) }\end{array}$ \\
\hline Rodrigues (2006) & $\begin{array}{l}\text { É aquela que, de forma proativa, analisa as mudanças no seu contexto específico de } \\
\text { atuação, identificando alterações de comportamento dos seus segmentos-alvo (alunos do } \\
\text { ensino médio, alunos de graduação, alunos de pós-graduação) e oportunidades em novos } \\
\text { segmentos de mercado (educação continuada, educação corporativa, educação a distância) } \\
\text { e monitora os movimentos da concorrência, buscando filtrar potenciais oportunidades em } \\
\text { eventos com conteúdo de ameaça. }\end{array}$ \\
\hline $\begin{array}{l}\text { Guenther e } \\
\text { Wagner (2008) }\end{array}$ & $\begin{array}{l}\text { Uma universidade empreendedora consiste em desenvolver mecanismos direto e indireto } \\
\text { para vincular a academia aos negócios, tais como transferência de tecnologia e escritórios } \\
\text { para isso, incubadoras e parques científicos, além do ensino ao empreendedorismo para } \\
\text { proporcionar habilidades e competências para atividades empreendedoras. }\end{array}$ \\
\hline $\begin{array}{l}\text { Guerrero } \\
\text { Urbano }(2011)\end{array}$ & $\begin{array}{l}\text { As universidades empreendedoras tornam-se } \\
\text { desenvolvimento regional, econômico e social. }\end{array}$ \\
\hline $\begin{array}{l}\text { Guerrero e } \\
\text { Urbano }(2012 a)\end{array}$ & $\begin{array}{l}\text { As universidades empreendedoras desempenham um papel importante como produtoras } \\
\text { de conhecimento e instituições de divulgação desse conhecimento, uma vez que a } \\
\text { universidade gera ideias e recursos humanos qualificados, enquanto a indústria tem os } \\
\text { recursos econômicos para transformar ideias em produtos economicamente úteis. }\end{array}$ \\
\hline $\begin{array}{l}\text { Guerrero e } \\
\text { Urbano }(2012 b)\end{array}$ & $\begin{array}{l}\text { Uma universidade empreendedora é definida como uma organização adaptável a } \\
\text { ambientes competitivos com uma estratégia comum para ser a melhor em todas as suas } \\
\text { atividades (por exemplo, têm boas finanças, seleciona bons alunos e professores, produz }\end{array}$ \\
\hline
\end{tabular}




\begin{tabular}{|l|l|}
\hline & $\begin{array}{l}\text { pesquisa de alta qualidade). Desta forma, são mais produtivas e criativas em estabelecer } \\
\text { laços entre o ensino e pesquisa. }\end{array}$ \\
\hline $\begin{array}{l}\text { Sam \& van der } \\
\text { Sijde (2014) }\end{array}$ & $\begin{array}{l}\text { Uma universidade empreendedora identifica e explora ativamente as oportunidades de } \\
\text { melhorar a si mesma (em relação à educação e à pesquisa) e ao meio ambiente (terceira } \\
\text { tarefa: transferência de conhecimento) e é capaz de gerenciar a dependência e o impacto } \\
\text { mútuo das três tarefas universitárias. Assim, ela é capaz de assumir vários papéis na } \\
\text { sociedade e no sistema de inovação (ecossistema), ligada a redes complexas de atores, } \\
\text { como indústrias privadas, financiadores e agências governamentais que estão ligadas entre } \\
\text { si, na busca de objetivos tecnológicos comuns e / ou ganhos econômicos mútuos. }\end{array}$ \\
\hline Mets (2015) & $\begin{array}{l}\text { A universidade empreendedora cria e implementa novos conhecimentos transferíveis e o } \\
\text { comportamento dos atores nesse processo (financiamento de P\&D, propriedade } \\
\text { intelectual, etc.) é empreendedor. O patenteamento por si só não é a prova do } \\
\text { comportamento empreendedor da universidade, mas essa é uma das primeiras etapas } \\
\text { direcionadas para implementar novos conhecimentos criados em negócios reais. }\end{array}$ \\
\hline
\end{tabular}

Figura 1. Definições de universidade empreendedora apontadas na revisão da literatura

Fonte: elaborado pelas autoras (2017)

Baseando-se nos conceitos apresentados na Figura 1, pode-se inferir que uma universidade empreendedora é um conjunto de características institucionais adaptadas e orientadas para um comportamento empreendedor (Clark, 1998).

Diferentemente da universidade tradicional que se preocupa apenas com ensino e pesquisa para si mesma (Etzkowitz, 2003), a universidade empreendedora é uma instituição com capacidade de mudar, de inovar, reconhecer e criar oportunidades (Kirby, 2002; Guerrero et al., 2006). Faz parte de um ecossistema empreendedor (Isenberg, 2011) e seus gestores e demais membros são proativos, estão dispostos a assumir riscos e responder aos desafios (Subotzky, 1999, Bratianu e Stanciu, 2010), visando a seu desenvolvimento interno (organizacional) e externo (seu entorno) (Chrisman et al., 1995, Röpke, 1998, Etzkowitz et al., 2000, Jacob et al., 2003, Guenther e Wagner, 2008).

As mudanças acima descritas oferecem oportunidades, bem como ameaças que levam à busca de parcerias nacionais e internacionais na construção de redes mais amplas de relacionamentos para aprovisionamento e aplicação de conhecimentos e para busca de recursos financeiros (Moroz \& Hindle, 2012). A pressão para a prestação de contas em termos de valor público também cresceu consideravelmente, continuam esses autores, uma vez que as universidades contribuem para o desenvolvimento econômico e social nacional, regional e local; na qualidade de ensino; e na mobilidade social (Moroz \& Hindle, 2012).

Yokoyama (2006) observou que as universidades envolvidas em atividades empreendedoras buscaram autonomia e passaram por mudanças organizacionais para responder às demandas internas e externas, que também exigiram parcerias com o setor privado. No entanto, a realização de atividades empreendedoras não transforma automaticamente uma universidade em empreendedora, quando essas atividades criam valor agregado a sua missão e vice-versa é que se configura uma universidade empreendedora.

\section{Metodologia}

Com o propósito de identificar um modelo teórico sobre as universidades empreendedoras, foi revisitada a literatura sobre a temática, principalmente seus modelos/características. Para tanto, foi necessário adotar alguns critérios relativos à busca

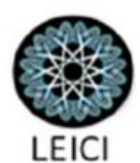


bibliográfica, seleção de artigos, definição de dimensões analíticas e enquadramento dos trabalhos de acordo com tais dimensões. De acordo com Mayer (2009), as revisões sistemáticas são textos científicos autônomos que têm o objetivo de realizar uma análise crítica e construtiva da literatura em um campo específico por meio da classificação, análise, comparação de um determinado tema.

O exame da literatura baseou-se nas diretrizes apontadas por Mayer (2009) e Cochrane (2012). Em princípio, foi consultada a base Scopus, pela seleção do termo "entrepreneur* universit*" (entre aspas), que se concentrou desde os estudos seminais até julho/2017, totalizando 254 artigos. Além disso, foram inclusos dois livros: 'Handbook on the entrepreneurial university' (Fayolle \& Redford, 2014) e 'Inovação e empreendedorismo na universidade' (Audy \& Morosini, 2006), totalizando 289 trabalhos.

Nessa etapa específica para extrair os elementos que caracterizam as universidades empreendedoras, os títulos, autores, periódicos e anos desses 289 estudos foram digitados em planilha Excel e inseridos no software Sphinx® Survey versão 5.1.0.4.

A partir da análise lexical nos títulos, palavras-chave e abstract, foram selecionados 42 artigos que continham as palavras 'modelo', 'framework', 'construção', 'desenho', 'arquitetura', 'anatomia', 'delineamento' e outras correlatas, a fim de identificar os elementos que caracterizam as universidades empreendedoras. No entanto, nem todos os artigos dessa primeira seleção continham os elementos para atender ao objetivo deste estudo. A busca foi ampliada a outras bases de dados e, ao final da busca, foram selecionados 13 artigos que atendiam ao propósito deste estudo.

Foi realizada a análise de conteúdo, identificando os elementos, fatores e características para proposição do modelo teórico (Figura 2). Esses elementos teóricos foram agrupados e relacionados em dimensões que, após serem refinados, embasaram a proposição do modelo teórico para análise empírica das universidades empreendedoras.

\begin{tabular}{|c|c|c|c|}
\hline Autores & Título & Periódico & Ano \\
\hline Clark & $\begin{array}{l}\text { Creating } \quad \text { Entrepreneurial } \\
\text { Organisational Pathways of Transformation. }\end{array}$ & $\begin{array}{l}\text { Oxford, Pergamon and Elsevier } \\
\text { Science. }\end{array}$ & 1998 \\
\hline Clark & $\begin{array}{l}\text { Delineating the character of the entrepreneurial } \\
\text { university }\end{array}$ & Higher Education Policy & 2004 \\
\hline Clark & Em busca da universidade empreendedora & $\begin{array}{l}\text { In: Inovação e empreendedorismo } \\
\text { na universidade. P. Alegre: } \\
\text { EDIPUCRS }\end{array}$ & 2006 \\
\hline Sporn & $\begin{array}{l}\text { Building adaptive universities: emerging } \\
\text { organisational forms based on experiences of } \\
\text { European and US universities }\end{array}$ & $\begin{array}{l}\text { Tertiary Education } \quad \text { and } \\
\text { Management }\end{array}$ & 2001 \\
\hline Kirby & $\begin{array}{l}\text { Creating Entrepreneurial Universities in the } \\
\text { UK: Applying Entrepreneurship Theory to } \\
\text { Practice. }\end{array}$ & Journal of Technology Transfer & 2006 \\
\hline Etzkowitz & The evolution of the entrepreneurial university & Technology and Globalisation & 2004 \\
\hline Etzkowitz & Anatomy of the entrepreneurial university & Social Science Information & 2013 \\
\hline $\begin{array}{l}\text { Salamzadeh; } \\
\text { Salamzadeh } \\
\text { \& Daraeil. }\end{array}$ & $\begin{array}{l}\text { Toward a systematic framework for an } \\
\text { entrepreneurial university: a study in Iranian } \\
\text { context with an IPOO model }\end{array}$ & $\begin{array}{l}\text { Global Business and Management } \\
\text { Research: An International Journal }\end{array}$ & 2011 \\
\hline Moroz & $\begin{array}{l}\text { University Entrepreneurship: Context, Process } \\
\text { and Performance. }\end{array}$ & Deakin University & 2012 \\
\hline
\end{tabular}




\begin{tabular}{|c|c|c|c|}
\hline OECD & $\begin{array}{l}\text { A Guiding Framework for Entrepreneurial } \\
\text { Universities }\end{array}$ & $\begin{array}{l}\text { OECD and the European } \\
\text { Commission }\end{array}$ & 2012 \\
\hline $\begin{array}{l}\text { Gibb; } \\
\text { Haskins \& } \\
\text { Robertson }\end{array}$ & $\begin{array}{l}\text { Leading the entrepreneurial university: } \\
\text { Meeting the entrepreneurial development } \\
\text { needs of higher education institutions. }\end{array}$ & 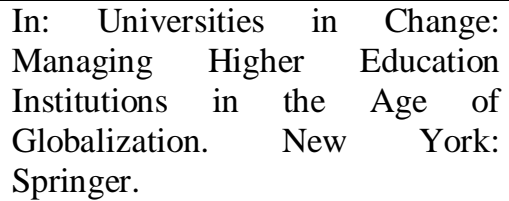 & 2013 \\
\hline $\begin{array}{l}\text { Guerrero; } \\
\text { Kirby \& } \\
\text { Urbano }\end{array}$ & $\begin{array}{l}\text { A literature review on entrepreneurial } \\
\text { universities: an institutional approach. }\end{array}$ & $\begin{array}{l}\text { In 3rd Conference of Pre- } \\
\text { communications to Congresses, } \\
\text { University of Barcelona. }\end{array}$ & 2006 \\
\hline $\begin{array}{l}\text { Guerrero; } \\
\text { Urbano \& } \\
\text { Salamzadeh }\end{array}$ & $\begin{array}{l}\text { Evolving entrepreneurial universities: } \\
\text { experiences and challenges in the Middle } \\
\text { Eastern context. }\end{array}$ & $\begin{array}{l}\text { In: Handbook on the } \\
\text { entrepreneurial university, Edward } \\
\text { Elgar Publishing }\end{array}$ & 2015 \\
\hline
\end{tabular}

Figura 2. Relação dos estudos analisados para proposição do modelo teórico

Fonte: elaborado pelas autoras (2017)

\section{A proposição do modelo teórico para as universidades empreendedoras}

Nesta seção serão apresentados os elementos identificados na revisão sistemática da literatura que caracterizam as universidades empreendedoras, evidenciados na análise de conteúdo iniciado primeiramente nos estudos publicados até dezembro de 2017.

Clark foi o pioneiro na identificação dos elementos centrais de uma universidade empreendedora (1998). Ele analisou como cinco universidades em cinco países europeus diferentes mudaram seu perfil e tornaram-se empreendedoras. Na verdade, ele identificou cinco elementos comuns para o caminho dessa transformação (Figura 3).

\section{Elementos}

Renda diversificada da universidade (outras fontes do governo, empresas privadas, patentes, associações de profissionais, de ex-alunos, etc.)

Capacidade fortalecida de gestão para o desenvolvimento (em todos os níveis hierárquicos) com administração nem centralizada nem descentralizadas.

Centros de pesquisa não-departamentais e programas de outreach

Centro acadêmico estimulado e modernizado

Cultura empreendedora envolvente - a construção de um sistema de crenças que abarca as características mais materiais identificadas nos quatro primeiros elementos de transformação

Figura 3. Elementos das universidades empreendedoras nos estudos de Clark. Fonte: Adaptado de Clark (1998; 2004; 2006).

Sporn (2001) apresentou estudo transnacional de estruturas universitárias adaptativas em relação a um ambiente socioeconômico em mudança. Com base nisso, são introduzidas novas formas organizacionais para universidades tornarem-se empreendedoras (Figura 4).

\begin{tabular}{|l|l|}
\hline \multicolumn{2}{|l|}{ Elementos } \\
\hline $\begin{array}{l}\text { As demandas ambientais podem ser definidas } \\
\text { como crise ou oportunidade pela instituição }\end{array}$ & $\begin{array}{l}\text { As universidades precisam desenvolver declaração de } \\
\text { missão e objetivos claros. }\end{array}$ \\
\hline Uma cultura empreendedora & Governança compartilhada \\
\hline Uma estrutura diferenciada & A liderança comprometida. \\
\hline A gestão profissionalizada & \\
\hline
\end{tabular}

Figura 4. Elementos das universidades empreendedoras identificados por Sporn em 2001. Fonte: Adaptado de Sporn (2001) 
Em estudo de caso na Universidade de Surrey, Kirby (2006) mostrou diferentes fatores estratégicos para promover atividades de empreendedorismo na universidade (Figura 5).

\begin{tabular}{|c|c|}
\hline Elemento & Definição \\
\hline Endossamento & Alto escalão e funcionários seniores funcionam como modelo aos demais \\
\hline Incorporação & Na universidade, faculdades / departamentos e pessoas. \\
\hline Implementação & Metas monitoradas \\
\hline Comunicação & Publicação e divulgação da estratégia e consulta sobre ela. \\
\hline $\begin{array}{l}\text { Incentivo } \\
\text { apoio }\end{array}$ & $\begin{array}{l}\text { Suporte rígido (laboratórios, pré-incubadoras, incubadoras, parques científicos, salas, } \\
\text { suporte informático, de escritório e financiamento). Suporte suave (capacitação, } \\
\text { orientação e aconselhamento, sinalização de fontes de suporte externo, suporte técnico e } \\
\text { gerencial) }\end{array}$ \\
\hline $\begin{array}{l}\text { Reconhecimento } \\
\text { e recompensa }\end{array}$ & Participação em ações, promoções, etc. \\
\hline Organização & $\begin{array}{l}\text { Grupos de ensino e pesquisa interdisciplinares, parcerias educativas, multidisciplinar } \\
\text { Centro de Empreendedorismo. }\end{array}$ \\
\hline Promoção & Competições de planos de negócios, empreendimentos "salões da fama", casos, etc. \\
\hline
\end{tabular}

Figura 5. Elementos das universidades empreendedoras identificados por Kirby. Fonte: Adaptado de Kirby (2006)

Em um de seus estudos preliminares, Etzkowitz (2004) apresentou um modelo de universidade empreendedora, no qual a universidade deveria assumir sua terceira missão - além do ensino e pesquisa, ela deveria ser promotora do desenvolvimento social e econômico, por meio da interação entre universidade-governo-empresa (Hélice tríplice). Esse modelo (Figura 6) foi atualizado em estudo posterior (Etzkowitz, 2013):

\begin{tabular}{|l|l|}
\hline Princípios & \multicolumn{1}{c|}{ Definição } \\
\hline Interação & $\begin{array}{l}\text { A universidade empreendedora interage estreitamente com a indústria e o governo, não é uma } \\
\text { universidade torre de marfim isolada da sociedade. }\end{array}$ \\
\hline Independência & $\begin{array}{l}\text { A universidade empreendedora é uma instituição relativamente independente, não é uma } \\
\text { criatura dependente de outra esfera institucional. }\end{array}$ \\
\hline Hibridização & $\begin{array}{l}\text { A resolução das tensões entre os princípios de interação e independência são um impulso para } \\
\text { a criação de formatos organizacionais híbridos para realizar ambos os objetivos. }\end{array}$ \\
\hline Reciprocidade & $\begin{array}{l}\text { Renovação contínua da estrutura interna da universidade como sua relação às mudanças da } \\
\text { indústria e do governo; e, da indústria e do governo ao rever sua relação com a universidade. }\end{array}$ \\
\hline
\end{tabular}

Figura 6. Elementos das universidades empreendedoras identificados por Etzkowitz. Fonte: Adaptado de Etzkowitz (2004; 2013).

Salamzadeh et al. (2011) propõem um framework para universidades empreendedoras (Figura 7), baseado em um sistema dinâmico, com insumos especiais, processos, resultados e visa mobilizar recursos, habilidades e capacidades para cumprir a terceira missão.

\begin{tabular}{|l|l|}
\hline & \multicolumn{1}{|c|}{ Elementos } \\
\hline Entradas & $\begin{array}{l}\text { Recursos (humanos, financeiros, físicos); regras/regulamentos; estrutura; missão; capacidades } \\
\text { empreendedoras; expectativas da sociedade, da indústria, do governo e do mercado. }\end{array}$ \\
\hline Processos & $\begin{array}{l}\text { Ensino; pesquisa; gestão; logística; comercialização; seleção (estudantes, professores, equipe); } \\
\text { financeiros; parcerias; interação multilateral; inovação, pesquisa e desenvolvimento (I, P\&D) }\end{array}$ \\
\hline
\end{tabular}

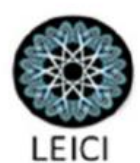




\begin{tabular}{|l|l|}
\hline Saídas & $\begin{array}{l}\text { Recursos humanos empreendedores (estudantes, professores, equipe); pesquisas efetivas } \\
\text { atendendo às demandas da sociedade; inovação/invenção; Redes e Centro de empreendedores } \\
\text { (incubadoras, parques tecnológicos, etc.) }\end{array}$ \\
\hline Resultados & Terceira Missão \\
\hline
\end{tabular}

Figura 7. Framework sistemático para universidade empreendedora baseado no modelo IPOO Fonte: Adaptado de Salamzadeh et al. (2011).

Moroz (2012) também enfatiza que os fatores externos e internos são responsáveis pelas universidades assumirem uma "mudança empreendedora" (Moroz, 2012, p. 35). Em um nível funcional, esse autor apresenta os elementos necessários para essa mudança (Figura 8).

\begin{tabular}{|l|}
\hline \multicolumn{1}{|c|}{ Elementos } \\
\hline Comercialização de conhecimento derivado de pesquisas realizado pela própria universidade \\
\hline Reforma das funços tradicionais de ensino, pesquisa e serviço comunitário, para atender às sociedade \\
\hline $\begin{array}{l}\text { Reformulação de políticas, incentivos e estruturas de governança, eliminando barreiras e encorajando } \\
\text { comportamentos à inovação do conhecimento }\end{array}$ \\
\hline O ensino do empreendedorismo na universidade \\
\hline
\end{tabular}

Figura 8. Elementos das universidades empreendedoras identificados por Moroz

Fonte: Adaptado de Moroz (2012).

O modelo apresentado pela Organização para a Cooperação e Desenvolvimento Econômico (Organization for Economic Cooperation and Development - OECD, 2012) foi desenvolvido para guiar as universidades europeias e enfatiza que elas devem ter o empreendedorismo como estratégia e um ecossistema empreendedor que coordene as atividades dentro da instituição e com as partes interessadas. Além disso, a instituição deve maximizar a autonomia e a apropriação individual das iniciativas empreendedoras, oferecendo educação empreendedora para a comunidade interna e externa à universidade (Figura 9).

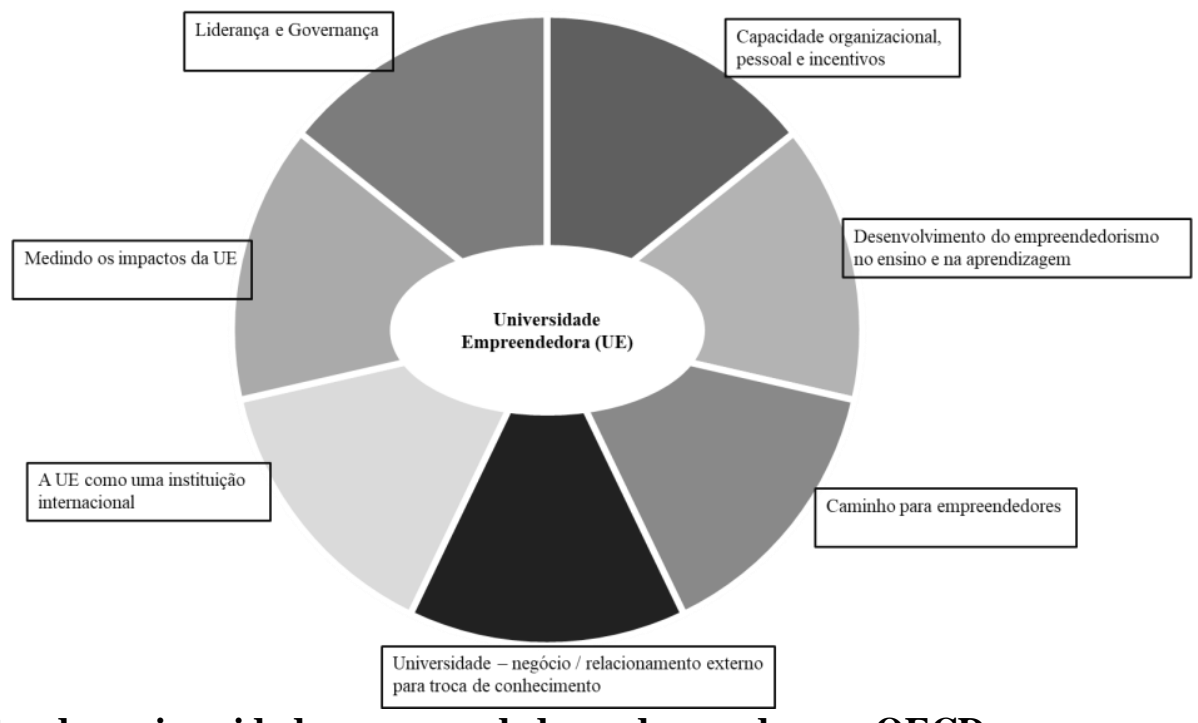

Figura 9. Elementos das universidades empreendedoras de acordo com OECD. Fonte: Adaptado de OECD (2012). 
Gibb et al. (2013) afirmam que no mundo das corporações globais e da tecnologia da informação, a universidade já não pode pretender ser a única, ou possivelmente a principal fonte de propriedade intelectual. Para manter seu status, também são necessárias parcerias com outras partes interessadas da sociedade (Figura 10). Baseando-se na experiência americana, asiática e europeia, esses autores apresentam as características da universidade empreendedora.

\begin{tabular}{|l|}
\hline \multicolumn{1}{|c|}{ Elementos } \\
\hline Possui autonomia financeira (aceitando cada vez menos os recursos do estado) \\
\hline Integra e partilha o conhecimentos e aprendizagem com a comunidade. \\
\hline Comercializa suas ideias para criar valor público na sociedade e isso não ameaça os valores acadêmicos. \\
\hline Organiza-se internamente para dar um impulso central mais forte ao empreendedorismo. \\
\hline Envolve-se ativamente com a comunidade. \\
\hline $\begin{array}{l}\text { Promove a criação de parques científicos, incubadoras, escritórios de transferência de tecnologia e } \\
\text { mecanismos de proteção intelectual, para abrir e integrar as relações universitárias }\end{array}$ \\
\hline Incentiva atividades interdisciplinares (criação de departamentos interdisciplinares e centros de P \& D) \\
\hline $\begin{array}{l}\text { Aceita a responsabilidade pelo desenvolvimento pessoal dos estudantes e do pessoal, em especial no que diz } \\
\text { respeito às futuras experiências sociais, de carreira e de aprendizagem ao longo da vida }\end{array}$ \\
\hline Recruta pessoal e nomeia líderes empreendedores como agentes de mudança \\
\hline Cria sistemas de recompensas (ensino, pesquisa, publicação, etc.) \\
\hline Expande o conceito de educação para o empreendedorismo em todas as faculdades. \\
\hline
\end{tabular}

Figura 10. Elementos das universidades empreendedoras identificados por Gibb et al.

Fonte: Adaptado de Gibb et al. (2013).

$\mathrm{Na}$ transformação das universidades tradicionais em empreendedoras, a liderança é considerada essencial (Gibb et al., 2013), pois cabe aos gestores focar no desenvolvimento institucional e pessoal, ampliando/estabelecendo parcerias institucionais (governo, empresas, outras instituições de ensino, etc.). Em particular, os acadêmicos devem ser capacitados para assumir riscos, bem como criar programas de recompensas em torno de novas formas de fazer as coisas. Um componente-chave é o gerenciamento de redes e de relacionamento, apontam Gibb et al. (2013), conforme demonstrado na Figura 11.

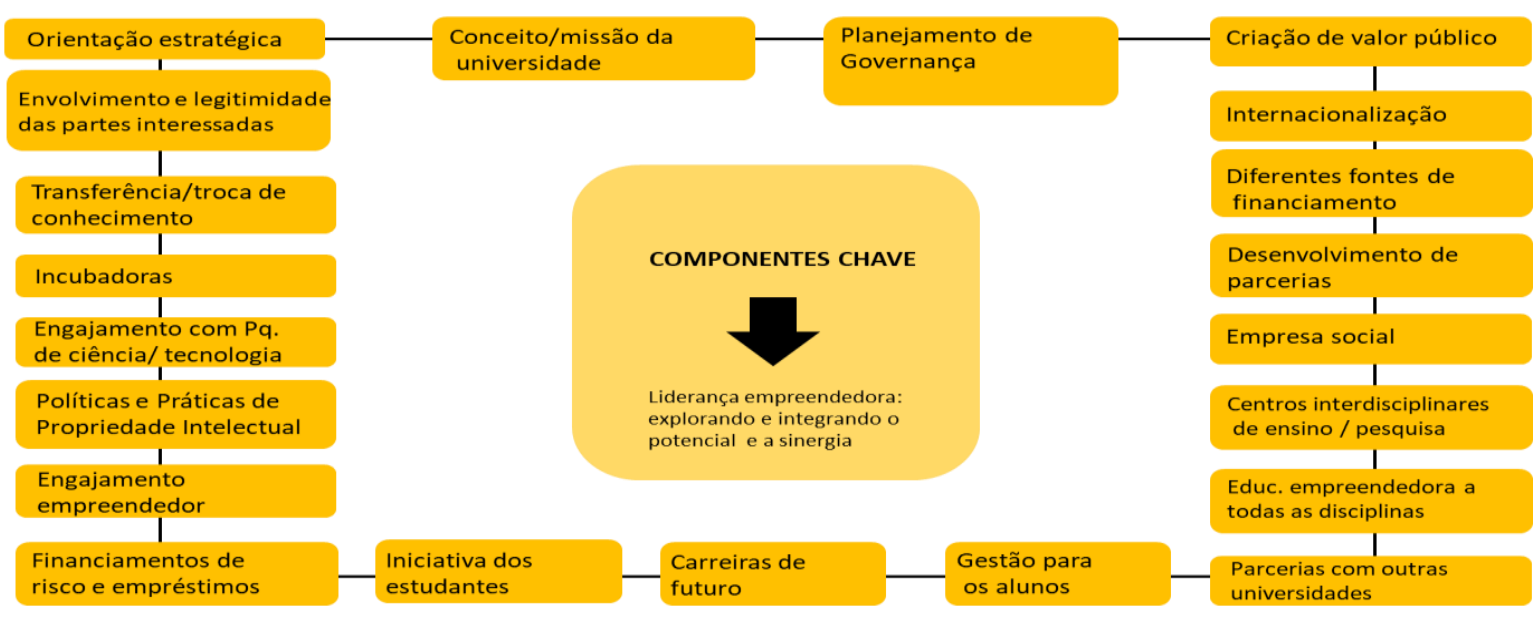

Figura 11. Framework das melhores práticas e conceitos apresentados por Gibb et al.

Fonte: Adaptado de Gibb et al. (2013). 
Guerrero et al. (2006) adotaram a Economia Institucional e a Visão Baseada em Recursos para apresentar o framework das universidades empreendedoras, focando em fatores internos (recursos e capacidades) e fatores ambientais (formais e informais), os quais facilitam ou dificultam a transformação de universidades em empreendedoras. Esses estudos foram apresentados em um framework recente (Guerrero et al., 2015), conforme Figura 12.

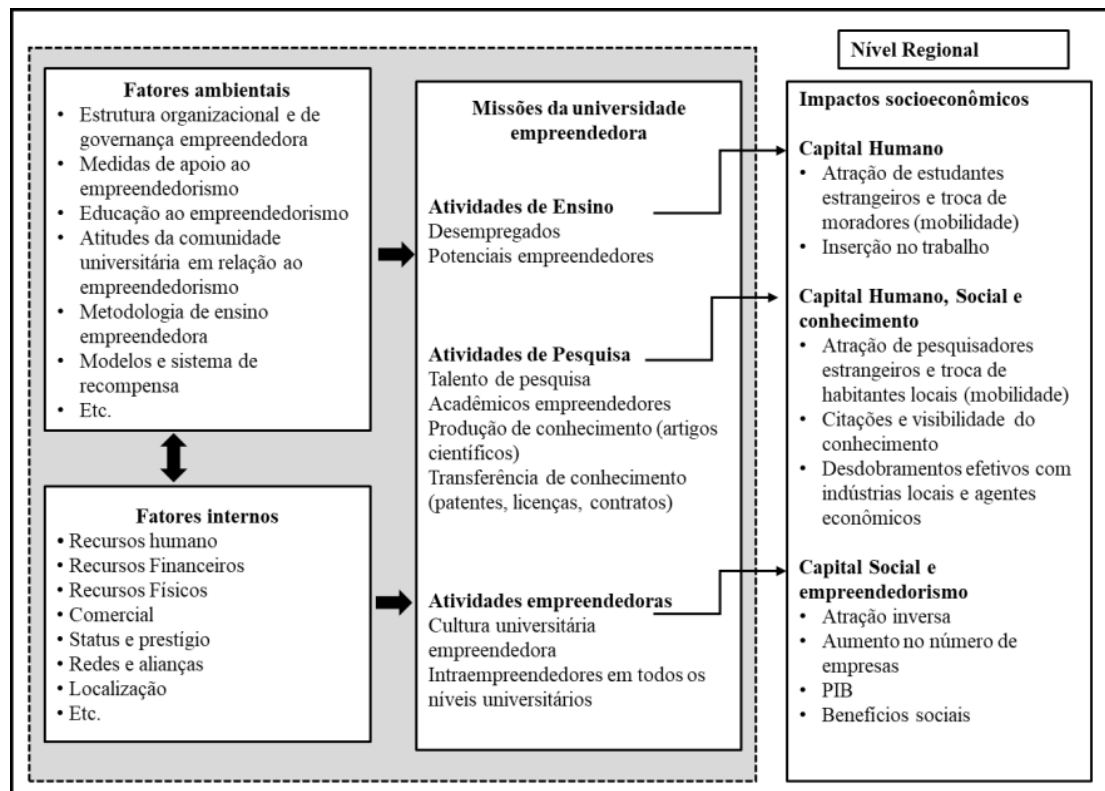

Figura 12. Framework de universidade empreendedora por Guerrero et al.

Fonte: Adaptado de Guerrero et al. (2015), baseado nos estudos de Guerrero \& Urbano (2011; 2012) e Urbano \& Guerrero (2013).

Complementando esse estudo com investigações anteriores, Guerrero et al. (2015) ampliam as discussões sobre os fatores ambientais, reforçando que a universidade empreendedora deve desenvolver uma estrutura flexível de gestão inovadora para reduzir os níveis de burocracia e apoiar as parcerias no ecossistema empreendedor que permita a interação e a definição de políticas e práticas para alcançar suas missões. Além disso, devem optar por medidas integradas por diferentes instrumentos e mecanismos para apoiar a criação de novas empresas internas e externas, instalações para pesquisa, grupos de pesquisa, escritórios de transferência de tecnologia e incubadoras. Apoiados nos estudos de Kirby (2004), indicam ainda programas educacionais para desenvolver o pensamento criativo e crítico e que empresários bem-sucedidos sejam modelos a serem seguidos.

Após a revisão sistemática realizada neste estudo, são apresentados os elementos identificados e sintetizados que caracterizam universidades empreendedoras (Figura 13). Concordando com Markuerkiaga et al. (2016), não há atualmente um consenso sobre como medir a universidade empreendedora. Na verdade, a partir da revisão da literatura, são detectados alguns esforços para caracterizá-las.

Quando se trata de descrever a organização das universidades empreendedoras, vários autores detalharam como essas universidades estão organizadas fisicamente com seus escritórios de transferência de tecnologia e propriedade intelectual, ou com centros de 
atendimento às demandas das indústrias, ou com seus parques tecnológicos. Porém, não são relatados como foram reorganizados os currículos, se existem programas interdisciplinares que englobem o ensino-pesquisa-extensão, ou que integrem e promovam a interação entre diferentes cursos e seus diferentes níveis (graduação, pós-graduação).

\begin{tabular}{|c|c|c|}
\hline Autores & Conceito & Elementos da UE \\
\hline 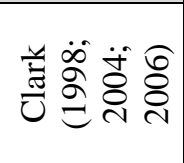 & $\begin{array}{l}\text { ealiza mudanças } \\
\text { n sua estrutura e } \\
\text { n sua cultura } \\
\text { ganizacional }\end{array}$ & $\begin{array}{l}\text { Ultura organizacional empreendedora; Núcleo de direção com gestão } \\
\text { inâmica; Inova currículos e programas; Renda diversificada (outras fontes } \\
\text { e financiamento); Centros de pesquisa não departamentais; Centros } \\
\text { cadêmicos. }\end{array}$ \\
\hline 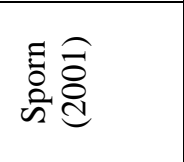 & $\begin{array}{l}\text { Adapta-se a um } \\
\text { ambiente } \\
\text { econômico e social } \\
\text { em mudança }\end{array}$ & $\begin{array}{l}\text { emandas ambientes (crise ou oportunidade); missão e objetivos claros; } \\
\text { lltura empreendedora; estrutura diferenciada; gestão profissionalizada; } \\
\text { overnança compartilhada; liderança comprometida; e alianças estratégicas. }\end{array}$ \\
\hline 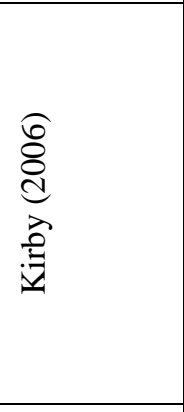 & $\begin{array}{l}\text { Fatores estratégicos } \\
\text { impulsionam o } \\
\text { empreendedorismo }\end{array}$ & $\begin{array}{l}\text { Endossamento (alto escalão e funcionários seniores funcionam como modelo } \\
\text { aos demais); Incorporação (na universidade, faculdades / departamentos e } \\
\text { pessoas); Implementação de metas monitoradas; Publicação e divulgação da } \\
\text { estratégia; Suporte rígido (laboratórios, pré-incubadoras, incubadoras, } \\
\text { parques científicos, salas de reuniões, suporte informático, serviços de } \\
\text { suporte de escritório e financiamento); Suporte suave (capacitação, } \\
\text { orientação e aconselhamento, sinalização para fontes de suporte externo, } \\
\text { suporte técnico e de gerenciamento); Competições; Recompensas e } \\
\text { premiaçôes; Grupos de ensino e pesquisa inter e multidisciplinares; Centro } \\
\text { de Empreendedorismo. }\end{array}$ \\
\hline N & $\begin{array}{l}\text { teração, } \\
\text { dependência, } \\
\text { bridização } \\
\text { ciprocidade }\end{array}$ & $\begin{array}{l}\text { erno e indústria (Hélice tríplice); Não dependente de outra } \\
\text { l; Criação de formatos organizacionais híbridos; } \\
\text { ua. }\end{array}$ \\
\hline 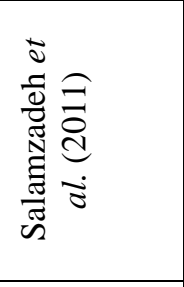 & $\begin{array}{l}\text { Mobiliza } \text { todos os } \\
\text { seus recursos, } \\
\text { habilidades r e } \\
\text { capacidades para } \\
\text { cumprir sua terceira } \\
\text { missão }\end{array}$ & $\begin{array}{l}\text { Mobiliza seus recursos (humanos, financeiros, físicos); regras/regulamentos; } \\
\text { estrutura; missão; capacidades empreendedoras; expectativas da sociedade, } \\
\text { da indústria, do governo e do mercado; no desenvolvimento de processos a } \\
\text { fim de obter recursos humanos empreendedores (estudantes, professores, } \\
\text { equipe); pesquisas efetivas atendendo às demandas da sociedade; } \\
\text { inovação/invenção; redes e centro de empreendedores (incubadoras, parques } \\
\text { tecnológicos, etc.) }\end{array}$ \\
\hline$\sum^{0} N \bar{d} \widehat{d}$ & $\begin{array}{l}\text { omercializa } \\
\text { nhecimento }\end{array}$ & $\begin{array}{l}\text { ercialização; seleção (estudan } \\
\text { s; interação multilateral; inova }\end{array}$ \\
\hline 己ิ & $\begin{array}{l}\text { Participa de redes e } \\
\text { o } \\
\text { empreendedorismo } \\
\text { é estratégico }\end{array}$ & $\begin{array}{l}\text { Liderança e governança; capacidade organizacional, pessoal e incentivos; } \\
\text { educação empreendedora; relacionamentos externos para troca de } \\
\text { conhecimento; internacionalização. }\end{array}$ \\
\hline 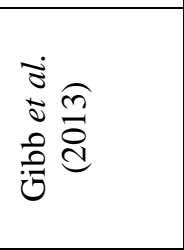 & $\begin{array}{l}\text { Universidade } \\
\text { parceira que gera } \\
\text { valor público }\end{array}$ & $\begin{array}{l}\text { Educação empreendedora; recursos humanos empreendedores (estudantes, } \\
\text { professores, equipe); orientaçãa estratégica; pesquisas efetivas atendendo às } \\
\text { demandas da sociedade; políticas de propriedade intelectual; financiamento } \\
\text { de risco e diferentes fontes de financiamento; inovação/invenção; redes e } \\
\text { centros interdisciplinares de empreendedores (incubadoras, parques } \\
\text { tecnológicos, etc.); internacionalização }\end{array}$ \\
\hline
\end{tabular}




\begin{tabular}{|c|c|c|}
\hline 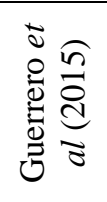 & $\begin{array}{l}\text { Catalisa o } \\
\text { desenvolvimento } \\
\text { regional, econômico } \\
\text { e social. }\end{array}$ & $\begin{array}{l}\text { Estrutura organizacional e de governança empreendedora, apoio ao } \\
\text { empreendedorismo, educação e metodologia ao empreendedorismo; sistema } \\
\text { de recompensa; redes e alianças; cultura empreendedora; internacionalização } \\
\text { (mobilidade de estudantes e atração de pesquisadores estrangeiros); } \\
\text { transferência de conhecimento. }\end{array}$ \\
\hline
\end{tabular}

Figura 13. Síntese dos elementos identificados na revisão de literatura para uma universidade empreendedora

Fonte: elaborado pelas autoras (2017)

Após a análise das características empreendedoras das universidades e seus elementos (Figuras 13), a Figura 14 apresenta, de forma sintetizada e por dimensões, a proposição do modelo de universidade empreendedora:

\begin{tabular}{|c|c|c|}
\hline Dimensões & Elementos & Autor(es) \\
\hline \multirow[t]{4}{*}{$\begin{array}{l}\text { Gestão } \\
\text { Estratégica }\end{array}$} & $\begin{array}{l}\text { Transição para gestão estratégica, em que } \\
\text { as oportunidades sejam em direção à } \\
\text { função econômica e social, orientadas para } \\
\text { a criação valores públicos, independente } \\
\text { dos recursos financeiros. }\end{array}$ & Clark; Kirby; Etzkowitz; OECD; Gibb et al. \\
\hline & $\begin{array}{l}\text { Liderança comprometida, dinâmica, } \\
\text { participativa e reforçada. }\end{array}$ & Clark; Moroz, OECD; Kirby. \\
\hline & $\begin{array}{l}\text { Cultura empreendedora integrada com } \\
\text { missão e objetivos claros. }\end{array}$ & Clark, Sporn; Guerrero et al. \\
\hline & $\begin{array}{l}\text { Renovação de currículos e programas para } \\
\text { uma educação empreendedora. }\end{array}$ & $\begin{array}{l}\text { Clark; Moroz; Etzkowitz; Gibb et al.; } \\
\text { Gerrero et al. }\end{array}$ \\
\hline \multirow[t]{5}{*}{$\begin{array}{l}\text { Infraestrutura } \\
\text { Diferenciada }\end{array}$} & Escritórios de TT e PI & $\begin{array}{l}\text { Clark; Sporn; Etzkowitz; Salamzadeh et al.; } \\
\text { Gibb et al.; Guerrero et al. }\end{array}$ \\
\hline & $\begin{array}{l}\text { Centros de atendimento às demandas da } \\
\text { sociedade, incluindo indústrias. }\end{array}$ & $\begin{array}{l}\text { Clark; Sporn; Kirby; Etzkowitz; Salamzadeh } \\
\text { et al.; Gibb et al.; Guerrero et al. }\end{array}$ \\
\hline & Parques tecnológicos & $\begin{array}{l}\text { Clark; Sporn; Kirby; Etzkowitz; Salamzadeh } \\
\text { et al.; Gibb et al.; Guerrero et al. }\end{array}$ \\
\hline & Incubadoras & $\begin{array}{l}\text { Clark; Sporn; Kirby; Etzkowitz; Salamzadeh } \\
\text { et al.; Gibb et al.; Guerrero et al. }\end{array}$ \\
\hline & $\begin{array}{l}\text { Centros de pesquisa modernos } \mathrm{e} \\
\text { interdisciplinares }\end{array}$ & $\begin{array}{l}\text { Clark; Sporn; Kirby; Etzkowitz; Salamzadeh } \\
\text { et al.; Gibb et al.; Guerrero et al. }\end{array}$ \\
\hline \multirow[t]{2}{*}{$\begin{array}{l}\text { Internacionaliz } \\
\text { ação }\end{array}$} & $\begin{array}{l}\text { Criação de programas de intercâmbio entre } \\
\text { estudantes e docentes }\end{array}$ & Moroz; OECD; Gibb et al.; Guerrero et al. \\
\hline & $\begin{array}{l}\text { Incentivos à publicação das pesquisas em } \\
\text { periódicos internacionais }\end{array}$ & Moroz \\
\hline \multirow{3}{*}{$\begin{array}{l}\text { Capital } \\
\text { financeiro }\end{array}$} & Orçamento (autonomia financeira) & Clark; Etzkowitz; Gibb et al \\
\hline & Captação de recursos externos & Clark; Etzkowitz; Gibb et al \\
\hline & Busca diferentes fontes de financiamento & Clark; Etzkowitz; Gibb et al \\
\hline \multirow[t]{4}{*}{$\begin{array}{l}\text { Comunidade } \\
\text { acadêmica } \\
\text { empreendedora }\end{array}$} & $\begin{array}{l}\text { Implantação de trabalho coletivo e } \\
\text { colaborativo entre os cursos e outras } \\
\text { instituições de ensino (compartilhamento } \\
\text { de práticas e pesquisas). }\end{array}$ & Moroz; Gibb et al \\
\hline & Programas para a educação empreendedora & Moroz; Gibb et al \\
\hline & $\begin{array}{l}\text { Capacita seus profissionais para uma } \\
\text { cultura empreendedora. }\end{array}$ & Moroz; Gibb et al \\
\hline & $\begin{array}{l}\text { Consultoria, desde a ideação até a criação } \\
\text { das startups. }\end{array}$ & Moroz \\
\hline
\end{tabular}




\begin{tabular}{|l|l|l|}
\hline \multirow{2}{*}{$\begin{array}{l}\text { Ecossistema } \\
\text { empreendedor }\end{array}$} & $\begin{array}{l}\text { Reconhecimento/premiação a docentes e } \\
\text { estudantes. }\end{array}$ & Moroz; Gibb et al, Guerrero et al. \\
\cline { 2 - 3 } & Parcerias internas e externas: & Moroz; Gibb et al.; Guerrero et al. \\
\cline { 2 - 3 } & Universidade x governo x indústria & Etzkowitz; Moroz; Gibb et al.; Guerrero et al. \\
\cline { 2 - 3 } & Universidade x empresas & Etzkowitz; Moroz; Gibb et al.; Guerrero et al. \\
\cline { 2 - 3 } & Universidade x outras IES & Moroz; Gibb et al.; Guerrero et al. \\
\hline
\end{tabular}

Figura 14. Proposição para o modelo teórico de universidade empreendedora

Fonte: elaborado pelas autoras (2017)

O modelo teórico apresentado (Figura 14) revela uma somatória de elementos agrupados em dimensões que caracterizam o perfil da universidade empreendedora, desde mudanças na forma de gestão das lideranças até mudanças na infraestrutura, tais como a criação de escritórios para facilitar o acesso dos membros externos à universidade, no qual as demandas advindas da sociedade possam ser atendidas, bem como seus membros internos (docentes e alunos) possam aplicar suas pesquisas externamente. Também torna necessário que os laboratórios sejam modernizados e os pesquisadores tenham condições estruturais para realizarem seus estudos.

As parcerias e redes de colaboração recebem destaque por outros estudiosos do empreendedorismo acadêmico (Sam \& van der Sijde,2014; Isenberg, 2011; dentre outros), uma vez que as universidades devem pertencer ao ecossistema empreendedor, no qual elas trabalham em conjunto com os governos, o setor privado e outras partes interessadas para repensar como desenvolver sociedades com indivíduos empreendedores, incorporando o empreendedorismo e a inovação em abordagens interdisciplinares e métodos de ensino interativos (Volkmann et al., 2009). Para tanto, devem reformular seus currículos e programas interdisciplinares para expandir a educação empreendedora a todos os cursos e disciplinas (Clark, 2004; Moroz, 2012; Gibb et al, 2013; Guerrero et al).

Quando se trata de descrever a organização das universidades empreendedoras, vários autores detalharam como estão organizadas fisicamente, com seus escritórios de transferência de tecnologia e propriedade intelectual, ou com centros de atendimento às demandas das indústrias, ou com seus parques tecnológicos. Porém, não são relatados como foram reorganizados os currículos, se existem programas interdisciplinares que englobem o ensinopesquisa-extensão, ou que integrem e promovam a interação entre diferentes cursos e seus diferentes níveis (graduação, pós-graduação).

Finalizando a análise da Figura 14, não foi identificado um modelo com todos os elementos apresentados na literatura. A maior parte desses estudos centram-se na transferência de tecnologia e nas relações das universidades com as indústrias e suas estruturas físicas. Também não foi identificado um modelo que apresentasse práticas empreendedoras integradas entre ensino, pesquisa, extensão e inovação, cujas ações contemplassem os diferentes valores que o empreendedorismo acadêmico pode agregar à comunidade.

\section{Considerações finais}

Pretende-se com este estudo qualitativo, que apresenta o modelo teórico para o estudo de universidade empreendedora, evidenciar as dimensões que as caracterizam e induzir outros estudos de caso que iluminem ainda mais o caráter das universidades empreendedoras que emergem e evoluem suas missões em ambientes complexos e diversificados.
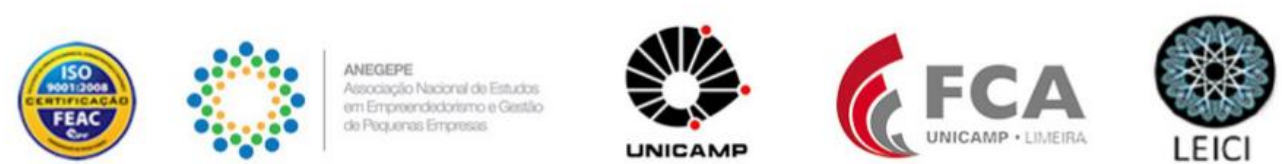
A partir dessa análise cumulativa das dimensões empreendedoras, é possível inferir que a universidade empreendedora é uma instituição que possui uma capacidade de mudança, por meio de sua inserção num sistema ecoempreendedor formado por governo, grupos empresariais/organizacionais e um corpo profissional institucional multidisciplinar, capaz de desenvolver conhecimento para a sociedade.

Além disso, possuem uma gestão estratégica participativa, na qual a comunidade acadêmica desenvolve conhecimentos, por meio do ensino, pesquisa e extensão, buscando modernizar sua infraestrutura e captar diferentes fontes de recursos financeiros.

Assim, espera-se que, ao analisar as dimensões aqui propostas, as universidades possam ampliar o papel social delas, juntamente com seu ecossistema empreendedor, e adotem ações voltadas para o desenvolvimento local, regional, nacional e internacional, integrando ensino, pesquisa, extensão e inovação.

Como contribuição acadêmica, este estudo relaciona as características das universidades empreendedoras e integra essas características em dimensões para compreensão das diferenças entre as universidades tradicionais e as empreendedoras e, pode servir de ponto de partida para outros estudos empíricos.

Como sugestões de estudos futuros, destaca-se a necessidade de pesquisas empíricas para validar os elementos identificados e/ou agregar outros elementos que possam compor uma universidade empreendedora.

Por último, vale ressaltar que o modelo teórico apresentado neste estudo não representa a finalização da caracterização das universidades empreendedoras, uma vez que, nas últimas décadas, as universidades tendem a se adaptar ao ambiente externo dinâmico e adotam estruturas (físicas, administrativas, pedagógicas, etc.) para atender às novas demandas requeridas pela sociedade.

\section{Referências}

Audy, J. L. N., Morosini, M. C. (2006) Inovação e empreendedorismo na universidade. Porto Alegre: EDIPUCRS

Barnes, T.; Pashby, I.: Gibbons, A. (2002), Effective university - industry interaction: a multicase evaluation of collaborative R\&D projects. European Management Journal, 20 (3), 272285.

Brasil (1996) Lei 9.394, de 20 de dezembro de 1996. Estabelece as Diretrizes e Bases da Educação Nacional. Diário Oficial da União. Brasília, DF, v. 134, n. 248, p. 27833-841, 23 dez. 1996.

Bratianu, C.; Stanciu, S. (2010). An overview of present research related to entrepreneurial university. Management \& Marketing, 5 (2), 117-134.

Chrisman, J.; Hynes, T.; Fraser, S. (1995). Faculty Entrepreneurship and Economic development: The Case of the University of Calgary". Journal of Business Venturing, 10: 26781.

Clark, R. B. (1998) Creating Entrepreneurial Universities. Organisational Pathways of Transformation. Oxford, Pergamon and Elsevier Science.

Clark, R. B (2004). Delineating the character of the entrepreneurial university. Higher Education Policy. 17 (4), 355-370. 
Clark, R. B. (2006) Em busca da universidade empreendedora. In: Audy, J. L. N., Morosini, M. C. (2006) Inovação e empreendedorismo na universidade. Porto Alegre: EDIPUCRS

Etzkowitz, H. (1983) Entrepreneurial Scientists and Entrepreneurial Universities in American Academic Science. Minerva, 21, 2-3.

Etzkowitz, H. (1998). The norm of entrepreneurial science: cognitive effects of the UniversityIndustry linkages. Research Policy, 27, 823-833.

Etzkowitz H (2002) Incubation of incubators: innovation as a triple helix of university-industrygovernment networks. Science and Public Policy, 29 (2), 115-128.

Etzkowitz H (2003) Research groups as "quasi-firms": the invention of the entrepreneurial university. Research Policy, 32(1), 109-121.

Etzkowitz H (2004). The evolution of the entrepreneurial university. Technology and Globalisation, 1(1), 64-77.

Etzkowitz, H (2013). Anatomy of the entrepreneurial university. Social Science Information, 2(3), 486-511

Etzkowitz, H.; Leydesdorff, L. (1998). The future location of research and technology transfer. Technology Transfer 24(2):111-123

Etzkowitz, H.; Webster. A.; Gebhart, C.; Terra, B. R. C. (2000). The future of the university and the university of the future: evolution of ivory tower to entrepreneurial paradigm. Research Policy, 29 (2), 109-123.

Fayolle, A.; Redford, D. A. (2015) Handbook on the entrepreneurial university, Edward Elgar Publishing.

Gibb, A (2005) Towards the Entrepreneurial University: Entrepreneurship education as a lever for change. Birmingham: National Council. Recuperado de http://ncee.org.uk em 10/11/2016

Gibb, A., Haskins, G. e Robertson, I. (2013). Leading the entrepreneurial university: Meeting the entrepreneurial development needs of higher education institutions. In: Altmann, A.; Ebersberger, B. (ed.) (2013) Universities in Change: Managing Higher Education Institutions in the Age of Globalization. New York: Springer.

Guenther, J; Wagner, K. (2008) Getting out of the ivory tower - new perspectives on the entrepreneurial university. European Journal of International Management, 2(4), 400-417

Guerrero, M.; Kirby D.; Urbano, D. (2006). A literature review on entrepreneurial universities: an institutional approach. II In 3 rd Conference of Pre-communications to Congresses, University of Barcelona, June.

Guerrero, M.; Toledano, N. e Urbano, D. (2011) Entrepreneurial universities and support mechanisms: a Spanish case study. Int. J. Entrepreneurship and Innovation Management, 13(2), 144-160.

Guerrero, M.; Urbano, D. (2011). The Creation and Development of Entrepreneurial Universities in Spain: An Institutional Approach, New York: Nova Science Publishers, Inc.

Guerrero, M. \& Urbano, D. (2012a). The development of an entrepreneurial university. Journal of Technology Transfer, 37(1), 43-74.

Guerrero, M.; Urbano, D. (2012b). Transferencia de conocimiento y tecnologia: Mejores prácticas en las universidades emprendedoras españolas, Gestion y Politica Publica, 1, 107-139 Guerrero, M.; Urbano, D.; Cunningham, J.; Organ, D. (2012) Entrepreneurial universities in two European regions: a case study comparison. Journal of Technology Transfer. 
Guerrero, M.; Urbano, D. \& Salamzadeh, A. (2015) Envolving entrepreneurial universities: experiences and challenges in the Middle Eastern context. In: Fayolle, A. \& Redford, D. A. (Ed.) Handbook on the entrepreneurial university, Edward Elgar Publishing.

Isenberg, D (2011) The entrepreneurship ecosystem strategy as a new paradigm for economy policy: principles for cultivating entrepreneurship, Babson Entrepreneurship Ecosystem Project, Babson College, Babson Park: MA

Jacob, M., Lundqvist, M. e Hellsmark, H. (2003) Entrepreneurial transformation in the Swedish university system: the case of Chalmers University of Technology. Research Policy, 32, 15551568

Kirby, D. (2002) Creating Entrepreneurial universities: a consideration. Working Paper. School of Management. University of Surrey.

Kirby, D. A. (2006) Creating Entrepreneurial Universities in the UK: Applying Entrepreneurship Theory to Practice. Journal of Technology Transfer, 31, 599-603.

Markuerkiaga, L.; Caiazza, R.; Igartua, J.I.; Errasti, N. (2016) Factors fostering students' spinoff firm formation: An empirical comparative study of universities from North and South Europe. Journal of Management Development, 35(6), 814-846.

Moroz, P. W. (2012) University Entrepreneurship: Context, Process and Performance. Deakin University.

OECD (2012) A Guiding Framework for Entrepreneurial Universities. OECD and the European Commission. Recuperado de https://www.oecd.org em 27/maio/2017

O'Shea, R.; Allen, T. J.; Morse, K.P.; O'Gorman, C. e Roche, F. (2007) Delineating the anatomy of an entrepreneurial university: The Massachusetts Institute of Technology experience. $R \& D$ Management, 37(1), 1-16.

Röpke, J. (1998). The Entrepreneurial University: innovation, academic knowledge creation and regional development in a globatized economy. Marburg

Salamzadeh, A.; Salamzadeh, Y.; Daraei, M. (2011). Toward a systematic framework for an entrepreneurial university: a study in Iranian context with an IPOO model, Global Business and Management Research: An International Journal, 3(1), 31-37

Sam, C.; van der Sijde, P. (2014) Understanding the concept of the entrepreneurial university from the perspective of higher education models. Higher Education, 68 (6):1-18

Sporn, B. (2001) Building adaptive universities: emerging organisational forms based on experiences of European and US universities. Tertiary Education and Management, 7(2), 121134.

Subotzky, G. (1999). Alternatives to the Entrepreneurial University: New Modes of Knowledge Production in Community Service Programs. Higher Education, 38(4): 401-440.

Volkmann, C., Wilson, K. E., Mariotti, S., Rabuzzi, D., Vyakarnam, S., \& Sepulveda, A. (2009). Education the Next Wave of Entrepreneurs: Unlocking entrepreneurial capabilities to meet the global challenges of the 21st century. A Report of the Global Education Initiative. Switzerland: World Economic Forum. Recuperado de http://www.heqco.ca em 20/nov/2017 Weerts D.J. (2007). Toward an engagement model of institutional advancement at public colleges and universities. Int $J$ Educ $A d v$ 7(2)

Yokoyama, K. (2006). Entrepreneurialism in Japanese and UK Universities: Governance, management, leadership, and funding. Higher Education, 52(3), 523-555.
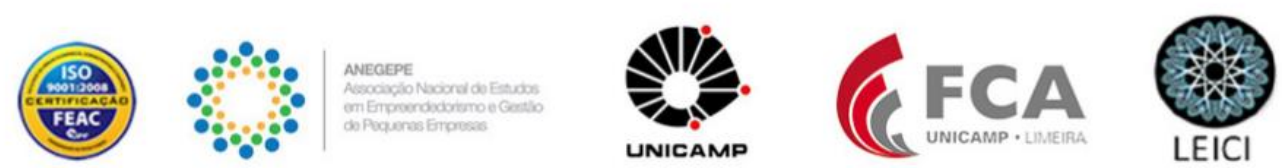